Foundation for Educational Research has finished its programme of evaluation.

Teaching languages at ordinary level (up to 16) has risen considerably during the past twenty years: the number of pupils offering Russian, for example, has increased nearly 600 -fold. If the first modorn language can be started in primary schools, it is hoped that more pupils will take a second modern language in secondary schools. Emphasis is now being laid on teaching the spoken language.

The growth of French teaching in primary schools has also led to a conspicuous growth of courses in colleges of education, and a handbook prepared in 1966 showed that French could be studied in 81 colleges. In recent years, language courses have also increased in further education, and it seems that some of the most successful courses have been those provided in direct response to an approach from a firm or firms in the area. Several universities now provide for the study and teaching of languages in new ways: for example, the report points out that in some universities the study and teaching of languages are linked with the study of linguistics, either within a unified centre or in a separate department.

\section{New IBP Chairman}

Dr W. Franklin Blatr, professor of zoology at the University of Texas, has been appointed chairman of the United States National Committee for the International Biological Programme (IBP). He succeeds Dr Roger Revelle, director of the Center for Population Studies at Harvard University. Dr Revelle was appointed chairman at the beginning of the three-year planning period for the IBP in 1964. Now that the IBP has moved into its five-year operational stage, Dr Revelle will act in an advisory capacity only, because of his commitments at Harvard and the National Academy of Sciences. Dr Revelle was recently appointed chairman of the academy's Science Organization Development Board and now acts, in effect, as Deputy Foreign Secretary of the Academy.

Dr Blair has been associated with the United States IBP programme from its beginning. One of his positions has been as co-chairman of the Subcommittee on Environmental Physiology. He has also organized the IBP integrated research programme on Convergent and Divergent Evolution. His main interest is vertebrate biology, particularly population geneties and the ecology and speciation of mammals, reptiles and amphibians.

\section{Drugs in School}

DRUG dependence in young people under eighteen years of age in the City of Westminster has recently been investigated by a social worker under Dr J. H. Briscoe-Smith, medical officer of health for the area. The investigation, started in February 1966, was prompted because it was felt that the Health Department should have as much information as possible on the extent of the problcm in the Westminster area, particularly as Soho lies within the city's bounds.

Much of the report seems to state the obvious, but it does at least prepare the ground for more extensive research. The aims of the survey were to estimate the sizo of the problem, whether gaps exist in the pro- vision at present made and to see how local authorities might help. Of the fifteen head teachers of secondary schools interviewed, nine had experienced problems with pill taking by children in their schools. While about half the teachers felt that many of the young people in the fourth and fifth forms experimented with pills at some time, the others considered that this was a pattern pursued by only a small minority. It does seem, however, that the problem is more serious in schools in the "old" City of Westminster. It is also known that there are a number of young heroin addicts around Victoria Station and a number of boys who were known to be taking pills at school in the Westminster area are now heroin addicts.

Of nine youth clubs investigated, six of the larger ones reported a drug problem although it was only a slight one in three of them. Between April 1965 and April 1967, 74 young people were convicted at the Westminster Juvenile Court on charges of possessing drugs, but of these only eight were residents in the area. As the report emphasizes, this is complicated by young people passing in and out of the area, which is in the centre of London.

On the whole, head teachers were against lectures on prevention because they felt that this might draw attention to drug taking and thereby create a challenge for young people. Instead, they thought that lectures for parents might be a better idea. Most schools felt that teachers would welcome more practical information on the matter and a book is to be published later this year containing coloured photographs of pills to enable teachers to recognize them. Four Rotary clubs in the Westminster area are hoping to set up an advice centre for drug addicts, and the Men's Social Services Branch of the Salvation Army is providing a hostel for young boys on probation for drug charges. By setting up an information service, it is suggested in the report that this might assist other workers in the field such as general practitioners and probation officers. A social work service offered by the Health Department to help people with problems of drug dependency is also suggested.

\section{On the Nature Trail}

OwNERS of land in Britain with areas of natural history interest should read Nature Trails, a handbook produced by the Nature Conservancy (distributed by Frederick Warne, Ltd., 5s.). This gives advice on the setting up of nature trails-the routes along which visitors can walk, with information provided by signs, posters, pamphlets and sometimes guides.

The first nature trail was set up in 1961, many more were instituted at the time of National Nature Week in 1963, and there are now about ninety of them. Some have been set up on national nature reserves by the Nature Conservancy; the Forestry Commission has some and others have been opened by county naturalist trusts and by private organizations and individuals. (A list of more than eighty nature trails can be obtained for $2 s$. from the Council for Nature.)

Where a good guide is available-and the handbook points out that a bad guide is worse than no guide at all-the tour can be varied according to ecological changes or the interests of the visitors. On the whole, a shortage of manpower makes guided trails rare; more common are the trails for which a pamphlet describes 